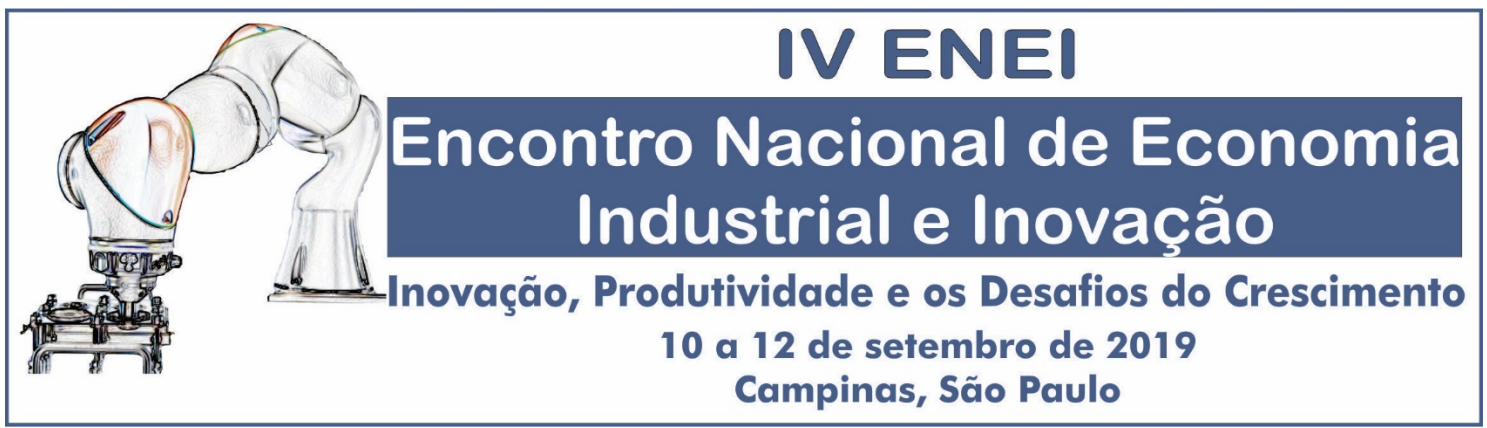

\title{
REFERENCIAL METODOLÓGICO PARA A MENSURAÇ̃̃O DOS FLUXOS INTERNACIONAIS DE TECNOLOGIA: UMA REVISÃO DA LITERATURA
}

\section{AUTORAS E FILIAÇÃO INSTITUCIONAL:}

Daniela Falcão - Instituto de Economia/UFRJ

Julia Paranhos - Instituto de Economia/UFRJ

Livia Freire - Instituto de Economia/UFRJ

\section{RESUMO}

Considerando a importância da transferência internacional de tecnologia no processo de desenvolvimento tecnológico dos países, este artigo pretende apresentar alguns indicadores que podem ser utilizados para mensurar esses fluxos internacionais de tecnologia, destacando suas potencialidades e possíveis limitações. Por meio de revisão da literatura, os indicadores sistematizados neste trabalho são o balaço de pagamentos dos países, os acordos de cooperação tecnológica, os contratos internacionais de transferência de tecnologia registrados no INPI e os dados sobre investimento direto estrangeiro. A análise limitou-se aos indicadores que mensuram os canais de transferência de tecnologia mediada pelo mercado e que possam ser comparáveis entre os diversos países e relativamente homogêneos ao longo do tempo.

Palavras-chave: Transferência Internacional de Tecnologia; Balanço de Pagamentos; Acordos de Cooperação Tecnológica; Contratos de Transferência de Tecnologia; Investimento Direto Estrangeiro.

\section{ABSTRACT:}

Considering the importance of the international transfer of technology in the technological development of the countries, this paper searches to present some indicators that can be used to measure these international flows of technology, highlighting their potentialities and possible limitations. Through literature review, the indicators systematized in this paper are the Country Balance of Payments, Technological Cooperation Agreements, technology transfer contracts registered in INPI and data on Foreign Direct Investment. The analysis was limited to the indicators that measure the market-mediated transfer channels of technology that can be comparable across countries and relatively homogenous over time.

Keywords: International Transfer of Technology; Balance of Payments; Technological Cooperation Agreements; Technology Transfer Contracts; Foreign Direct Investment.

\section{Área ABEIN:}

\section{Inovação e mudanças técnica, organizacional e institucional}

\subsection{Transferência de tecnologia e Processos de aprendizado}

JEL: 033 


\section{INTRODUÇÃO:}

Em diferentes momentos históricos, a transferência internacional de tecnologia (TIT) foi um instrumento utilizado com bastante sucesso por diversos países em processo de catch-up tecnológico. Este foi o caso, por exemplo, dos EUA no século XIX e do Japão e da Coreia em meados do século XX - cada um apresentando estratégias e características particulares. Tais países, além de superarem o atraso tecnológico em relação às economias mais industrializadas, promoveram o fortalecimento de suas capacidades/aptidões tecnológicas, transformando-se em economias afluentes e avançadas.

Com as mudanças tecnológicas derivadas do Paradigma das Tecnologias da Informação e Comunicação (TICs) e a crescente globalização que promoveu o aumento da competitividade e internacionalização da produção, o acesso a tecnologias estrangeiras vem tornando-se uma estratégia ainda mais importante para o suprimento das necessidades tecnológicas das empresas e a manutenção de seu dinamismo (NARULA; ZANFEI, 2005 apud CARNEIRO, 2017, p. 457).

Nesse novo contexto, o desejo de estabelecer uma base tecnológica mais forte e, consequentemente, competir eficazmente nos atuais mercados de alta tecnologia, levou as empresas das economias de industrialização recente (EINs) a buscarem alianças estratégicas de tecnologia com parceiros (estrangeiros) competentes, dispostos a transferir seu know-how tecnológico, através de fluxos de tecnologia unidimensionais, como licenças e acordos de fornecimento secundário (DUYSTERS; HAGEDOORN, 2005, p.283).

A fim de exemplificar a crescente relevância que a importação de tecnologias estrangeiras tem adquirido no processo de desenvolvimento das empresas e dos países no novo paradigma, Ester Carneiro (2017, p.458) salienta que em 2009, os gastos mundiais totais com o licenciamento de tecnologias estrangeiras responderam por $1 / 4$ dos gastos totais dos países com P\&D. Assim, podemos notar como os fluxos tecnológicos internacionais, cada vez mais, têm sido utilizados como instrumento essencial e complementar para o alcance de trajetórias tecnológicas superiores, juntamente com os esforços nacionais, como investimento em P\&D e outras políticas de inovação.

Desde a década de 1960, diversos estudos se debruçaram em analisar como países de rápida industrialização do Leste e Sudeste asiáticos alcançaram um catch-up bem sucedido e como a TIT foi um elemento de destaque e relevância nesse processo. Entretanto, pouca atenção tem sido dada a análise dos fluxos internacionais de tecnologia nos anos mais recentes - década de 2000. Diversas questões poderiam ser discutidas em maior profundidade pelos pesquisadores para uma melhor compreensão e análise desses fluxos, a saber: quais os seus principais canais de transferência, como mensurá-los, quais são os indicadores disponíveis, quais são os aspectos positivos e negativos da escolha de cada indicador? (CARNEIRO, 2017).

Este artigo propõe discutir tais questões, pois consideramos que mapear os diferentes indicadores que mensuram os fluxos tecnológicos muito contribui para a realização de estudos de casos que procuram analisar a distribuição geográfica dos fluxos mundiais de tecnologia, as relações de dependência tecnológica entre os países e, posteriormente, tentar discutir o sucesso ou fracasso de determinadas estratégias de TIT.

Os fluxos internacionais de tecnologia podem se manifestar por meio de diferentes canais e modos de transferência, nem sempre observáveis ou mensuráveis, acarretando a ausência de uma metodologia única e consolidada para sua quantificação. Entretanto, é possível utilizar proxies para avaliar um ou mais aspectos que componham estes fluxos (CARNEIRO, 2017).

Sendo assim, o objetivo geral deste artigo é apresentar alguns indicadores para a mensuração desse movimento, destacando as potencialidades e possíveis limitações de se utilizar cada indicador. Dado este objetivo, pretende-se também discutir i) o conceito de tecnologia e sua transferência internacional, a partir da teoria neoschumpeteriana; ii) um panorama geral dos diversos canais de TIT ao longo dos três paradigmas tecnológicos: da Revolução Industrial, do paradigma da produção em massa e das TICs, e iii) que o sucesso da transferência de tecnologia está profundamente relacionado à construção de uma capacidade tecnológica local para adaptar e modificar a tecnologia, como as experiências históricas dos países industrializados evidenciaram. 
Metodologicamente, será realizada uma revisão da literatura sobre o tema da TIT e sobre os principais indicadores utilizados e suas particularidades para a mensuração dos fluxos tecnológicos. A primeira seção do artigo discute as questões propostas nos objetivos específicos, ou seja, apresenta uma revisão teórica mais geral sobre o processo de transferência internacional de tecnologia e suas particularidades. Em seguida, também com base na literatura, busca-se sistematizar os indicadores referentes aos canais formais de TIT, tendo em vista que mensurar a transferência de tecnologia informal em escala internacional é uma tarefa de difícil execução. De forma mais específica, os indicadores aqui analisados são o Balanço de Pagamentos dos países, os Acordos de Cooperação Tecnológica, os dados sobre Investimento Direto Estrangeiro (IDE) e, em âmbito nacional, os Contratos Internacionais de Transferência de Tecnologia registrados pelo Instituto Nacional da Propriedade Industrial (INPI). De maneira geral, espera-se que este trabalho possa complementar outros estudos que se concentram em analisar e mensurar os fluxos internacionais de tecnologia e, consequentemente, enriquecer ainda mais essa discussão.

\section{TRANSFERÊNCIA INTERNACIONAL DE TECNOLOGIA}

Existem diferentes conceitos de tecnologia disponíveis na literatura. Neste trabalho, optou-se por utilizar a definição da tradição neoschumpeteriana, que apresenta uma visão mais aprofundada e abrangente do termo tecnologia. Para Dosi (1982), o significado desse conceito deve ser associado a um conjunto de conhecimentos, tanto diretamente 'práticos' (relacionados com problemas e dispositivos concretos) quanto teóricos (mas aplicáveis a prática, mesmo que não necessariamente já aplicados), knowhow, métodos, procedimentos e experiência de sucesso e fracassos e também, naturalmente, dispositivos e equipamentos físicos que corporificam os avanços no desenvolvimento de uma tecnologia em uma determinada atividade de solução de problemas. Portanto, tecnologia, nesta perspectiva, está vinculada a um conjunto de procedimentos inseridos em um determinado paradigma tecnológico, estando presente nos profissionais e na rotina das empresas.

A tecnologia pode ser transferida entre empresas e entre regiões e países por meio de diferentes mecanismos, desde canais mais formais, no qual o mercado exerce poder de regulação, até canais mais informais ou não mediados pelo mercado (KIM, 1999).

Os canais mediados pelo mercado incluem: investimento direto estrangeiro (IDE); licenciamento e a compra/venda de tecnologia; importação de bens e serviços; acordos de cooperação para desenvolver novas tecnologias, como joint ventures; integração dos atores em cadeias globais de produção e inovação, assistência técnica e instalação de laboratórios de P\&D em subsidiárias no exterior (KIM, 1999; FU, PIETROBELLI, SOETE, 2011; CARNEIRO, 2017).

Os canais não mediados pelo mercado, por sua vez, incluem: engenharia reversa; cópia; pirataria; espionagem industrial; fluxo de mão-de-obra qualificada através da migração, viagens e intercâmbio de estudantes e trabalhadores; seminários e conferências internacionais; disseminação de novas descobertas por meio de artigos, livros e resultados de pesquisa disponibilizados gratuitamente na internet, bibliotecas públicas ou documentos de patentes; e a participação em redes de inovação aberta (Ibidem).

Segundo Chiarini e Silva (2017) os principais canais de transferência de tecnologia foram mudando ao longo do tempo para responder as mudanças tecnológicas ocorridas. De acordo com essa perspectiva, "um canal protagonista em certo momento histórico passa a ser coadjuvante em outros, pois a tecnologia dominante apresenta características que requerem canais específicos para que seja transferida" (Ibidem, p.691). Esses autores argumentam que

quando a tecnologia estava enraizada nos trabalhadores e com a sofisticação das máquinasferramenta mecânicas, a tecnologia passou a estar nelas corporificadas, por isso eram transferidos tanto os trabalhadores quanto as máquinas para que a tecnologia (indiretamente) fosse transferida. À medida que a tecnologia passou a ser relativamente mais complexa e mais produtiva e cada vez mais dependente de novos conhecimentos científicos, a transferência tecnológica e de conhecimento passou a ser possível mediante meios codificados (licenciamentos pelo uso da propriedade intelectual, por exemplo). Finalmente, com a tecnologia se tornando cada vez mais sistêmica, possibilitando a fragmentação da produção em cadeias globais de valor, foi possível a 
transferência de normas e métodos de produção, por meio de IDE (CHIARINI, SILVA, 2017, p.710).

O quadro abaixo resume os principais canais da TIT em cada paradigma tecnológico ${ }^{1}$. Chiarini e Silva (2017) salientam que esses canais apresentados foram os principais encontrados em cada paradigma estudado, no entanto, isso não significa dizer que somente eles foram utilizados, pois a TIT, além de depender da evolução da própria tecnologia e do paradigma tecnológico em questão, também depende do 'grau' de desenvolvimento do país importador e das relações entre diferentes atores em âmbito internacional.

Quadro 1: Principais canais da TIT em cada paradigma tecnológico

\begin{tabular}{|c|c|c|c|}
\hline $\begin{array}{l}\text { Paradigmas } \\
\text { Tecnológicos }\end{array}$ & $\begin{array}{l}\text { Revoluções } \\
\text { Tecnológicas } \quad \grave{a} \quad L a \\
\text { Carlota Perez }\end{array}$ & Período & Principais Canais da TIT \\
\hline $\begin{array}{l}\text { Revolução Industrial } \\
\text { (Primeira Revolução } \\
\text { Industrial) }\end{array}$ & Revolução Industrial & $\begin{array}{l}\text { Século } \\
\text { XVIII a } \\
\text { meados do } \\
\text { século } \\
\text { XIX }\end{array}$ & $\begin{array}{l}\text { Mobilidade de trabalhadores, } \\
\text { treinamento, espionagem, } \\
\text { contrabando e a importação } \\
\text { legal de ferramentas e } \\
\text { máquinas. }\end{array}$ \\
\hline $\begin{array}{l}\text { Paradigma da } \\
\text { Produção em Massa } \\
\text { (Segunda Revolução } \\
\text { Industrial) }\end{array}$ & $\begin{array}{l}\text { Era do Vapor e das } \\
\text { Ferrovias; Era do } \\
\text { Aço, Eletricidade e } \\
\text { Engenharia Pesada; } \\
\text { Era do Petróleo, } \\
\text { Automóveis } \\
\text { Produção em Massa. }\end{array}$ & $\begin{array}{l}\text { Meados do } \\
\text { século } \\
\text { XIX a } \\
\text { meados do } \\
\text { século XX }\end{array}$ & $\begin{array}{l}\text { Anterior + Exportação de bens } \\
\text { e serviços, estabelecimento de } \\
\text { organizações de vendas desses } \\
\text { bens no exterior (transferindo } \\
\text { conhecimento organizacional), } \\
\text { concessão de licenças para o } \\
\text { uso de suas patentes, marcas e } \\
\text { know-how a empresas } \\
\text { estrangeiras (e suas filiais no } \\
\text { exterior). }\end{array}$ \\
\hline $\begin{array}{l}\text { Paradigma das TICs } \\
\text { (Terceira Revolução } \\
\text { Industrial) }\end{array}$ & $\begin{array}{l}\text { Era da Informação e } \\
\text { das } \\
\text { Telecomunicações }\end{array}$ & $\begin{array}{l}\text { Meados do } \\
\text { século XX } \\
\text { em diante }\end{array}$ & $\begin{array}{l}\text { Anterior }+ \text { Transferência de } \\
\text { normas e métodos de } \\
\text { produção, por meio de IDE e } \\
\text { por meio da participação em } \\
\text { cadeias globais de valor. }\end{array}$ \\
\hline
\end{tabular}

Fonte: CHIARINI, SILVA, 2017, p.711.

Outra classificação apontada pela literatura é a necessidade de se fazer uma distinção entre transferência de tecnologia vertical e horizontal. Segundo Mansfield (1975), "a transferência vertical de tecnologia ocorre quando a informação é transmitida da pesquisa básica para a pesquisa aplicada, da pesquisa aplicada para o desenvolvimento e do desenvolvimento para a produção". Essas transferências ocorrem em ambos os sentidos, e a forma da informação muda à medida que se move ao longo desta dimensão. Por outro lado, a transferência horizontal de tecnologia ocorre quando "a tecnologia usada em um local, organização ou contexto é transferida e usada em outro local, organização ou contexto". Mansfield salienta ainda que os problemas envolvidos na transferência de tecnologia de um país para outro são bem diferentes quando a transferência é vertical e horizontal (MANSFIELD, 1975, p.372).

\footnotetext{
${ }^{1}$ Os autores optaram por utilizar a proposição analítica de 'três paradigmas' apresentados por Paulo Tigre ao invés das 'cinco revoluções tecnológicas’ teorizadas por Carlota Perez, pois não encontraram diferenças históricas marcantes no que concerne à TIT que justificasse a separação analítica em muitos períodos o que dificultaria encontrar elementos que diferenciassem um período do outro.
} 
Nathan Rosenberg (2006) destaca que apesar de existir uma vantagem básica de ser um país retardatário, uma vez que tais países podem industrializar-se por meio da simples transferência de tecnologias já existentes, sem precisar reinventá-las, a TIT não é um processo fácil. Isso porque, tipicamente, foram e são necessários altos níveis de habilidade e competência técnica nos países recebedores. Como ele bem salienta:

\begin{abstract}
A transferência bem sucedida de tecnologias não se resume a uma questão de se transportar uma peça de maquinaria de uma localização geográfica para outra. Ela envolve com frequência questões muito mais sutis de seleção e discriminação, e uma capacidade de adaptar e de modificar, antes que a tecnologia possa funcionar efetivamente no novo ambiente socioeconômico (ROSENBERG, 2006, p.367).
\end{abstract}

Essa questão apontada por Rosenberg é ressaltada em praticamente todos os estudos sobre a TIT. Segundo os historiadores econômicos, o conhecimento tecnológico, em vez de algo que existe no domínio público e pode ser explorado por qualquer pessoa em qualquer lugar gratuitamente, é profundamente enraizado nas capacidades específicas das empresas privadas e suas redes/ambientes e, portanto, não é facilmente transferível (FAGERBERG, SRHOLEC, VERSPAGE, 2010). Nesse sentido, não há nada de automático em termos de catch-up por meio da transferência de tecnologia, pelo contrário, ela requer muito esforço e capacitação.

Teóricos do mainstream econômico argumentam que os países em desenvolvimento poderiam se beneficiar da difusão de tecnologias industriais sem incorrer nos custos da inovação tecnológica. Sobre essa questão, Bell e Pavitt (1993) ressaltam que o processo de catch-up - ou seja, o processo de convergência/emparelhamento tecnológico dos países 'retardatários' em relação aos mais desenvolvidos não é garantido de forma alguma e depende do equilíbrio entre inovação e difusão e de até que ponto os países retardatários estão equipados com as capacidades necessárias para alcançar uma acumulação tecnológica.

No entanto, a difusão envolve mais do que a aquisição de máquinas e equipamentos e a assimilação do know-how operacional relacionado. Também envolve mudanças técnicas contínuas, muitas vezes incrementais, pelas quais as inovações originais são (i) moldadas para se adequarem a condições específicas de uso em uma ampla gama de situações específicas, e (ii) aprimoradas para atingir padrões de desempenho superiores àqueles originalmente alcançados. Ou seja, o processo de inovação continua durante a fase de difusão da tecnologia (BELL, PAVITT, 1993).

Nesse sentido, fica evidente a importância do envolvimento ativo na mudança técnica até mesmo das firmas, indústrias e economias que adquirem tecnologia desenvolvida em outros lugares. Portanto, Bell e Pavitt (1993) destacam que a capacidade dos países em desenvolvimento de absorverem e adaptarem a tecnologia importada para alcançaram um catch-up tecnológico e atingirem um maior grau de desenvolvimento vai depender de dois estoques de recursos: (i) as habilidades, conhecimentos, experiências e estruturas institucionais que compõem a capacidade de um país de gerar e gerenciar mudanças na tecnologia industrial que utiliza (denominado de capacidades tecnológicas), e (ii) os bens de capital, conhecimento e habilidades de trabalho necessárias para produzir bens industriais com tecnologia 'dada' (ou seja, capacidade de produção industrial de um país). Por 'acumulação tecnológica' os autores entendem como o acúmulo do primeiro desses estoques de recursos.

Apresentando uma perspectiva semelhante, Cohen e Levinthal (1990) argumentam que a capacidade de uma empresa reconhecer o valor de novas informações externas, assimilá-las e aplicá-las a fins comerciais é fundamental para suas capacidades inovadoras. Eles rotulam essa capacidade como uma capacidade de absorção da empresa e que está intimamente relacionada à construção de uma capacidade de aprendizagem. Isso porque a aquisição e o uso de tecnologias envolvem tanto o conhecimento codificado quanto o tácito, que é difícil de ser transferido apenas por manuais, requerendo assim certas habilidades dos profissionais e das empresas que podem ser adquiridas por meio de treinamentos, educação formal e experimentação. Finalmente, o que Cohen e Levinthal concluem é que sem passar pela etapa do aprendizado, da aquisição de capacidades tecnológicas próprias, as tecnologias não serão transferidas de maneira bem sucedida. 
Fu, Pietrobelli e Soete (2011), por sua vez, discorrem que apesar do potencial oferecido pela globalização, os benefícios da TIT serão melhor maximizados quando os esforços de inovação local, a presença de estruturas institucionais e de governança modernas e as aquisições de conhecimento estrangeiro funcionarem em paralelo. As experiências das economias hoje industrializadas demonstram que os esforços de inovação local e estrangeira são complementares. Confiar unicamente em um deles não seria ideal para o desenvolvimento de capacidades tecnológicas e para o processo de catch-up, uma vez que, "sem esforços de inovação endógena proativos, a tecnologia estrangeira permanece apenas tecnologia estática embutida em máquinas importadas que nunca se transformarão em capacidade tecnológica real" (Ibidem, p. 1210. Tradução Livre). Em suma, o que estes autores ressaltam é que o incentivo as atividades endógenas de inovação e P\&D continuam a ser uma peça central e indispensável para uma estratégia de assimilação e adaptação da tecnologia estrangeira e a aceleração do aprendizado e capacitação tecnológica (p.1211)

Portanto, a TIT proporciona uma modernização tecnológica do país importador, ampliando a capacidade de produção, sem, no entanto, garantir a ampliação da aptidão tecnológica doméstica e o rompimento do subdesenvolvimento. Como Freeman ressalta, a aquisição de tecnologia e conhecimentos podem eventualmente ser eficiente no curto prazo, mas não se constituem como a melhor opção no longo prazo já que o desenvolvimento não deriva apenas da mera importação de tecnologias, mas da capacidade doméstica de se estabelecerem sistemas tecnológicos inter-relacionados em evolução, capazes de gerar sinergias para processos de desenvolvimento sustentado (FREEMAN, SOETE, 2005 apud CHIARINI, SILVA, 2017, p.712).

\section{INDICADORES PARA A MENSURAÇÃO DOS FLUXOS INTERNACIONAIS DE TECNOLOGIA:}

Como discutido na primeira parte do trabalho, os fluxos internacionais de tecnologia (FIT) englobam múltiplos canais de transferência, versando desde aqueles menos formais, não mediados pelo mercado, como observação e engenharia reversa, até aqueles mais formalizados, como a contratação de serviços técnicos e o licenciamento de tecnologia. Dada essa variedade/característica, existe uma certa dificuldade de mensurar todos os canais pelos quais a transferência de tecnologia flui entre as fronteiras nacionais. Ademais, os FIT frequentemente são analisados por meio de seus diferentes canais de transferência, sendo geralmente limitados por determinada abrangência geográfica e/ou temporal. Tais análises ainda subdividem-se em abordagens qualitativas e quantitativas, além da investigação dos fluxos internacionais de tecnologias incorporadas e desincorporadas (SANTOS, 2014, p.153).

Dado este desafio, o objetivo aqui é sintetizar os principais indicadores e suas respectivas bases de dados/fontes de informação referentes aos fluxos internacionais de tecnologia que foram apontadas e utilizadas em alguns estudos acadêmicos. No entanto, a análise limita-se aos indicadores que mensuram os canais de transferência de tecnologia mediada pelo mercado, tendo em vista a complexidade e dificuldade de medir/verificar empiricamente os fluxos informais de tecnologia. Além disso, é realizada uma breve discussão acerca da funcionalidade, metodologia, potencialidades e limitações dos indicadores e bases de dados sistematizados. Tendo em vista que diversas metodologias podem ser utilizadas para mensurar a transferência internacional de tecnologia, este trabalho procura apresentar indicadores que possam ser comparáveis entre os diversos países e relativamente homogêneos ao longo do tempo.

O principal referencial teórico que subsidia nossa análise é a tese de doutorado da Ester Carneiro Santos (2014), que avaliou as principais fontes de informação para mensuração dos fluxos internacionais de tecnologia, destacando três em particular: os dados relativos do balaço de pagamentos dos países, dos acordos de cooperação tecnológica e de estudos de casos. Além dessa metodologia, outro indicador bastante utilizado pela literatura são as estatísticas sobre investimento direto estrangeiro (IDE), assim, as bases de dados sobre IDE também são discutidas aqui. Ademais, será discutido brevemente os contratos internacionais de transferência de tecnologia registrados no INPI, pois também apresentam dados relevantes para a mensuração desses fluxos no Brasil.

Ester Santos (2014) ao analisar os diversos estudos que procuram discutir as transferências tecnológicas internacionais que ocorrem de maneira desincorporada, concluiu que, em linhas gerais, as 
fontes utilizadas por estes podem ser divididas em três grandes grupos. O primeiro refere-se aos fluxos tecnológicos entre países contabilizados por meio de seus Balanços de Pagamentos (BPs). Dentro deste grupo encontram-se o Balanço de Pagamentos Tecnológicos (Technological Balance of Payments - TPB) da OECD, dados sobre royalties e taxas de licenciamento (R\&L) presentes nos BPs dos países e também compilados pelo Fundo Monetário Internacional (FMI), os balanços de pagamentos tecnológicos de países individuais (como Brasil e Portugal, por exemplo) e, por fim, outras informações sobre trocas tecnológicas internacionais como o financiamento de P\&D realizada externamente e serviços técnicos (SANTOS, 2014, p. 154).

O segundo grupo diz respeito aos fluxos de tecnologia realizados por meio de acordos de cooperação tecnológica (ACTs) entre diferentes países. Segundo a autora, as principais bases que apresentam informações desse tipo são mantidas por universidades e/ou instituições governamentais de pesquisa e por agências privadas. Nesse grupo as principais bases são: MERIT-CATI (Cooperative Agreements and Technology Indicators), o The CORE (COoperative REsearch) database, o NCRA-RJV (National Cooperative Research Act - Research Joint Ventures), o Thompson Financial SDC (Securities Data Company) Platinum database, o Royalty Source ${ }^{\circledR}$, o RoyaltyStat ${ }^{\circledR}$, além de outras voltadas a setores específicos, como o BIOSCAN e o RECAP (HAGEDOORN, et al., 2000 apud SANTOS 2014, p.153).

O terceiro grupo é composto por estudos de caso sobre transferências internacionais de tecnologia, onde são encontradas diversas informações mais específicas sobre as trocas tecnológicas realizadas internacionalmente por meio de variados canais e por grupos específicos de países (SANTOS, 2014, p.154). No entanto, Ester Carneiro ressalta que os casos analisados nesses estudos acabam apresentando abrangência temporal e/ou geográfica reduzida, acarretando em uma certa dificuldade para fazer generalizações e observar o fenômeno da TIT sob um conjunto de indicadores unificados (CARNEIRO, 2017, p. 465).

Sobre os Acordos de Cooperação tecnológica, destacamos o MERIT-CATI que foi o indicador utilizado no estudo de Duysters e Hagedoorn (2005) para analisar a transferência e o aprendizado tecnológico por meio de alianças estratégicas de tecnologia. Em linhas gerais, o Merit-Cati é uma base de dados sistêmicos, estabelecida desde meados da década de 1980, que contém informações de mais de dez mil acordos de cooperação tecnológicos entre empresas localizadas em mais de 60 países (NAVARETTI, CARRARO, 1996; DUYSTERS; HAGEDOORN, 2005). Nessa base de dados, apenas se consideram acordos entre empresas que incluam algum arranjo para transferência de tecnologia ou pesquisa conjunta. Por exemplo, os acordos de fornecimento secundário e de licenciamento, informações sobre joint ventures, em que se recebe tecnologia de, pelo menos, um dos parceiros, ou joint ventures que possuem algum programa de P\&D. É excluída da coleta de dados as joint ventures envolvendo apenas produção ou marketing, uma vez que, o objetivo do indicador é analisar formas de cooperação e de acordos, em que uma atividade inovadora combinada ou uma troca de tecnologia faça, ao menos, parte do contrato. Consequentemente, também são excluídas as parceiras que regulamentam apenas a divisão de instalações de produção, o conjunto de padrões e acordos de fixação de preços e de barreiras de acesso (DUYSTERS; HAGEDOORN, 2005, p.291).

Santos $(2014$, p. 191) salienta que apesar de incluir acordos em nível internacional, as informações contidas nas bases dos ACTs, de maneira geral, são viesadas em torno dos grandes grupos multinacionais, em virtude de seus mecanismos de coleta de informação.

No que diz respeito aos dados referentes aos indicadores dos BPs, eles mensuram pagamentos/recebimentos pelo uso, distribuição e reprodução de ativos intangíveis protegidos por direitos de propriedade intelectual como patentes, know-how, invenções, designs, trademark, franquias, software, além de pagamentos/recebimentos por assistência técnica e compra/venda de P\&D realizada externamente. No entanto, eles apresentam algumas diferenças substanciais.

Em relação aos BPs de países individuais, estes procuram fazer uma análise das trocas tecnológicas realizadas pelo país à luz da sua realidade e com o tipo de informação que eles tem disponível. Assim, apesar de trazerem informações mais contextualizadas e aderentes para a realidade de cada país, acabam por dificultar a realização de estudos comparativos, uma vez que, cada um deles apresentam uma metodologia própria (SANTOS, 2014). 
O indicador TPB- OECD compila dados de 1980 em diante, mas se restringe as informações dos países membros da OCDE. Basicamente propõe aos seus países membros a utilização de uma metodologia comum em seus BPs que reúne três informações principais: i) 'troca em técnica', englobando dados acerca de uma ampla gama de fluxos de direitos de propriedade intelectual; ii) trocas referentes a serviços com conteúdo técnico como serviços de consultoria em engenharia e estudos técnicos; e iii) fluxos de financiamento externo da atividade de $\mathrm{P} \& \mathrm{D}$, ou seja, financiamento à $\mathrm{P} \& \mathrm{D}$ realizada fora do país de residência do agente financiador (Ibidem).

Os dados sobre royalties e taxas de licenciamento (R\&L), por outro lado, possuem uma maior abrangência geográfica (apresenta registro de pelo menos 163 países), temporal (desde 1956 até 2010) e institucional (contempla as transações realizadas por todas as firmas em território nacional e lançadas em seus balanços, ao contrário do TBP- OCDE, que é restrito a alguns grupos e setores quando as informações utilizadas advêm de surveys nacionais). O FMI é o órgão que sistematiza os dados sobre R\&L em nível internacional e, além disso, alguns países apresentam informações com maiores níveis de detalhamento, como os EUA e o Japão, por exemplo. Em linhas gerais, a base de dados do FMI permite a análise de como esses fluxos evoluem entre as economias ao redor do globo e evidencia as mudanças em seus padrões ao longo do tempo (SANTOS, 2014).

Apesar dos fluxos de R\&L serem compilados de maneira individualizada por cada país, o que gera possibilidades de desvio entre os valores totais de origem e destino (ou pagamentos e recebimentos) entre os países envolvidos, Ester Santos ressalta que eles possuem uma homogeneidade relativamente alta ao longo do tempo e entre os países (Ibidem). Além disso, uma das maiores potencialidades dos dados sobre R\&L é que eles podem indicar:

pelo lado do país que realiza esses pagamentos, seu esforço na busca por uma ampliação de sua
capacidade tecnológica via aquisição de tecnologia estrangeira, no contexto de suas estratégias de
catching up tecnológico e/ou manutenção de suas vantagens competitivas. Já pelo lado do país
recebedor podem sinalizar o seu alcance de melhores posições tecnológicas ou seu ingresso em
trajetórias tecnológicas superiores onde os resultados desses esforços possuem valor para seus
parceiros (SANTOS, 2014, p.164).

Outro indicador importante para mensurar a transferência internacional de tecnologia, sendo inclusive um dos mais utilizados nos estudos de casos sobre TIT, são os dados relativos ao IDE que, em linhas gerais, pode ser definido como o aporte de recursos que vem do exterior para ser aplicado na estrutura produtiva de outro país (WOLFFENBÜTTEL, 2006 apud REIS et al. 2017). Ressalta-se que o IDE está estritamente relacionado às atividades das empresas multinacionais (EMNs), as quais realizam um papel importante no processo de TIT. A tecnologia transferida das EMNs por meio de IDE pode incluir uma das seguintes formas ou uma combinação delas: bens de capital, treinamento de mão de obra, direitos de propriedade industrial e know how (REIS et al. 2017).

Apesar do IDE não ser o mecanismo de transferência de tecnologia mais eficaz para o país receptor, uma vez que existem muitas pré-condições necessárias para atender a um processo eficaz de transferência de tecnologia (como ressaltado na primeira seção do trabalho), ele é o canal que possui mais informações sobre dados estatísticos, apresentando diversas bases de dados compiladas por vários organismos internacionais. Por exemplo, Rios et al (2017), em seu estudo sobre o impacto do Acordo TRIPS sobre a TIT para os países em desenvolvimento, utilizaram os relatórios anuais da UNCTAD que abrangem informações sobre o fluxo de IDE em um conjunto de países. Por sua vez, Túlio Chiarini em sua tese, para medir o fluxo de IDE para P\&D das filiais americanas fora dos EUA utilizou dados disponibilizados no Science \& Engineering Indicators do National Center for Science and Engineering Statistics (NCSES) - National Science Foundation.

Por fim, em âmbito nacional, destacamos os contratos internacionais de transferência de tecnologia registrados no INPI. Em linhas gerais, contratos de transferência de tecnologia são documentos que formalizam as questões tecnológicas e financeiras que envolvem tais transações (AMORIM; SOUZA, 2011). O registro, ou averbação, de tais contratos no Brasil foi instituído pela Lei no 4.131 de 1962 com o objetivo inicial de controlar as remessas de lucros e royalties ao exterior. Nas décadas de 70 e 80 , o seu foco muda para a regulação dos mercados de tecnologia, em alinhamento com a política nacional de 
desenvolvimento industrial. Com a criação do INPI, em 1970, e a instituição do Novo Código da Propriedade Industrial, em 1971, a responsabilidade pelo registro de tais contratos é transferida para a recém-criada autarquia (INPI, 2016).

As informações sobre os fluxos tecnológicos desses contratos são encontradas no sistema BuscaWeb disponibilizado no website do INPI. Os contratos internacionais de transferência de tecnologia registrados no INPI são classificados em algumas categorias, que demonstram como a TIT ocorreu entre as partes do contrato. É importante destacar que muitas vezes um contrato engloba diversas categorias de transferência, entre elas (INPI, 2018):

1) Licença para Exploração de Patentes - contratos que objetivam a licença para exploração da patente ou do pedido de patente depositado no INPI pelo titular da patente ou pelo depositante;

2) Cessão de Patente - contratos que tem como objetivo a cessão da patente ou do pedido de patente depositado no INPI, implicando na transferência da titularidade;

3) Fornecimento de Tecnologia - contratos que possuem como finalidade a aquisição de conhecimentos e de técnicas não amparados por direitos de propriedade industrial concedidos ou depositados no Brasil. O contrato deve compreender o conjunto de informação e dados técnicos para permitir a fabricação dos produtos e/ou processos;

4) Prestação de Serviços de Assistência Técnica e Científica - contratos destinados à prestação de serviços de assistência técnica que estipulam as condições de obtenção de técnicas, métodos de planejamento e programação, bem como pesquisas, estudos e projetos destinados à execução ou prestação de serviços especializados quando relacionados à atividade fim da empresa, assim como os serviços prestados em equipamentos e/ou máquinas no exterior, quando acompanhados por técnico brasileiro e/ou gerarem qualquer tipo de documento, como por exemplo, relatório. Alguns serviços técnicos são dispensados de registro pelo INPI por não caracterizarem transferência de tecnologia.

5) Franquia - contratos que se destinam à concessão temporária de modelo de negócio que envolva o uso de marcas e/ou exploração de patentes, prestação de serviços de assistência técnica, combinadamente ou não, com qualquer outra modalidade de transferência de tecnologia necessária para a consecução do objetivo da parte contratante.

No entanto, apesar de necessário para produzir efeitos perante terceiros, o registro dos contratos de transferência de tecnologia no INPI não é obrigatório, o que pode enviesar a utilização desse indicador para a mensuração dos FIT no Brasil. Além disso, a averbação desses contratos é realizada principalmente para fins econômicos, sendo remessa de royalties ao exterior e dedutibilidade fiscal os maiores exemplos (AMORIM, SOUZA, 2011; RIBEIRO, BARROS, 2014).

\section{CONSIDERAÇÕES FINAIS:}

Existem diversas abordagens para mensurar a transferência internacional de tecnologia entre países e empresas. Essa diversidade de metodologias decorre principalmente das distintas nuances buscadas por cada estudo em suas análises: seja para a investigação de determinada região ou país, seja para a análise de determinado setor ou um determinado canal de transferência. Nesse sentido, os estudos têm se utilizado de diferentes fontes de informação para a análise do mesmo fenômeno, trazendo, por vezes, dificuldade na compreensão dos tipos de dados existentes e mesmo sobre suas potencialidades e limitações (SANTOS, 2014, p, 153).

Assim, este artigo parte da perspectiva de que fazer uma revisão da literatura sobre os principais indicadores e bases de dados para mensurar a transferência formal de tecnologia entre as fronteiras nacionais é relevante, pois, nos ajuda a apresentar argumentos mais consistentes para justificar a escolha de determinado indicador para as mais diversas possibilidades de análise e estudos de caso. Isto porque nenhum indicador, por si só, vai mensurar todos os canais pelos quais a transferência de tecnologia pode fluir entre as fronteiras nacionais e também não consegue englobar todos os atores envolvidos nesse processo, além das distintas abrangências geográficas e temporais. Qualquer indicador vai apresentar potencialidades e limitações, no entanto, a depender do objetivo proposto pela pesquisa, determinado 
indicador e base de dados, ou um conjunto deles, podem ser mais eficientes e adequados para a análise a ser desenvolvida.

De modo resumido, é possível afirmar que: (i) os dados relacionados aos BPs dos países incluem dados acerca de ampla gama de direitos de propriedade intelectual, no entanto, para fins de estudos comparativos, destacam-se os dados sobre royalties e taxas de licenciamento do FMI por ser a base que possui uma maior abrangência geográfica, temporal e institucional; (ii) as informações de ACTs trazem compreensão sobre acordos de nível internacional entretanto tais dados geralmente são viesados em torno dos grandes grupos multinacionais, principais fontes de tais acordos; (iii) os estudos de caso são ricas fontes de informação tendo em vista as especificidades que esses estudos contemplam, todavia as limitações na abrangência temporal e/ou geográfica, características de tal tipo de pesquisa, criam obstáculos a generalizações; (iv) o IDE, apesar de ser o canal de TIT com mais informações estatística disponível, está estritamente relacionado às atividades das empresas multinacionais, assim como ocorre com os ACTs, além disso é também um dos menos eficientes quando se analisa seu benefício para os países receptores, uma vez que, como ressaltado, existem muitas pré-condições necessárias para atender a um processo eficaz de transferência de tecnologia; e (v) os contratos de transferência de tecnologia averbados no INPI, apesar de conterem informações estratégicas sobre as tecnologias que estão sendo internacionalmente comercializadas, não são obrigatoriamente registrados no Brasil (exceto para fins econômicos), limitando seu potencial como fonte de informação.

Assim sendo, estudos que buscam analisar a dependência tecnológica das economias menos desenvolvidas para com os países da Tríade, por exemplo, poderiam utilizar o indicador de royalties e taxas de licenciamento. Já se o objetivo é investigar as particularidades da formação de alianças estratégicas de tecnologias entre determinadas empresas, as fontes de informações provenientes dos acordos de cooperação tecnológica poderiam ser mais adequadas, assim como os contratos internacionais de transferência de tecnologia registrados no INPI, no caso do Brasil. Ademais, levando em consideração a experiência chinesa recente, os dados relativos ao investimento direto estrangeiro poderiam ser utilizados para contabilizar os fluxos de tecnologia entre as empresas multinacionais e as empresas locais de países menos desenvolvidos a fim de avaliar a contribuição do processo de investimento estrangeiro para o desenvolvimento tecnológico do país receptor. Percebemos assim que as possibilidades de utilização dos indicadores e das bases de dados apresentadas neste trabalho são diversas. Logo, as questões apontadas acima poderiam ser objeto de discussão para pesquisas futuras sobre TIT e muito iriam contribuir com esse campo de estudos.

\section{REFERÊNCIAS:}

AMORIM, R. C. R.; DE SOUZA, C. G. Technology transfer in Brazil: a study of contracts for the exploitation of patents registered by the Brazilian Patent Office, 2001-2006. Information Development, v. 27, n.1, p. 46-57, 2011.

BELL, M.; PAVITT, K. Technological accumulation and industrial growth: Contrasts between developed and developing countries. Industrial and Corporate Change, v. 2, n. 1, p. 157-210, 1993.

CARNEIRO, E. Fluxos tecnológicos internacionais. In: RAPINI, M., SILVA, L., MOTA E ALBUQUERQUE, E. (Org) Economia da ciência, tecnologia e inovação: fundamentos teóricos e a economia global. Curitiba: Editora Prismas, 2017.

CHIARINI, T. Transferência internacional de tecnologia: interpretações e reflexões. $O$ caso brasileiro no Paradigma das TICs na última década do século XX e no alvorecer do século XXI. Tese (Doutorado em Ciência Econômica). Universidade Estadual de Campinas, UNICAMP, Campinas. 2014.

CHIARINI, T; SILVA, A. L. Os principais canais de transferência internacional de tecnologia em diferentes paradigmas tecnológicos: implicações para a superação do subdesenvolvimento. Econ. soc., Campinas, v. 26, n. 3, p. 691-719, Dec. 2017. 
COHEN, W; LEVINTHAL, D. Absorptive Capacity: A New Perspective on Learning and Innovation. Administrative Science Quarterly, v, 35, n. 1, p.128-152, 1990.

DOSI, G. Technological paradigms and technological trajectories: a suggested interpretation of the determinants and directions of technical change. Researchpolicy, v. 11, n. 3, p. 147-162, 1982.

DUYSTERS, G.; HAGEDOORN, J. A colaboração tecnológica internacional: suas consequências para as economias de industrialização recente. In: KIM, Linsu.; NELSON, Richard. (Orgs.) Tecnologia, aprendizado e inovação: as experiências das econômicas de industrialização recente. Campinas: Editora Unicamp, 2005 (Coleção Clássicos da Inovação, $1^{\text {a }}$ edição em inglês 2000).

FAGERBERG, J; SRHOLEC, M; VERSPAGEN, B. The role of innovation in development. Review of Economics and Institutions, v. 1, n. 2, 2010.

FU, X; PIETROBELLI, C; SOETE, L. The role of foreign technology and indigenous innovation in the emerging economies: technological change and catching-up. World Development, v. 39, n. 7, p. 1204-1212, 2011.

INPI - INSTITUTO NACIONAL DA PROPRIEDADE INDUSTRIAL. História da averbação de contratos no INPI. 2016 Disponível em: <http://www.inpi.gov.br/menuservicos/transferencia/historia-daaverbacao-de-contratos-no-inpi>. Acesso: 08 out. 2018.

INPI - INSTITUTO NACIONAL DA PROPRIEDADE INDUSTRIAL. Tipos de Contratos. 2018. Disponível em: http://www.inpi.gov.br/menu-servicos/transferencia/tipos-de-contratos. Acesso: 08 out. 2018.

KIM, L. Building technological capability for industrialization: analytical frameworks and Korea's experience. Industrial and Corporate Change, v. 8, n. 1, p. 111-136, 1999.

MANSFIELD, E. International technology transfers: forms, resource requirements, and policies. The American Economic Review, Vol. 65, No. 2, p.372-376, 1975.

NAVARETTI, G. B; CARRARO, C. From learning to partnership : multinational research and development cooperation in developing countries. Policy, Research working paper, no. WPS 1662. Washington, DC: World Bank, 1996

RIBEIRO, M. C. P.; BARROS, M. F. E. Contratos de transferência de tecnologia: Custos de transação versus desenvolvimento. Revista de Informação Legislativa, Brasília, v. 51, n. 204, p. 43-66, 2014.

RIOS, L. et al. Propriedade intelectual e transferência internacional de tecnologia na OMC: Implicações para os países em desenvolvimento. Gestão e Sociedade, v. 11, n. 29, p. 1850-1881, 2017.

ROSENBERG, N. As transferências internacionais de tecnologia: implicações para os países industrializados. In: ROSENBERG, Nathan. Por dentro da caixa preta: tecnologia e economia. Campinas: Editora Unicamp, 2005 (Coleção Clássicos da Inovação, $1^{a}$ edição em inglês 1982).

SANTOS, E. C. C. Fluxos internacionais de tecnologia e a divisão internacional do trabalho: uma abordagem evolucionária. Tese (Doutorado em Economia) - Centro de Desenvolvimento e Planejamento Regional, Universidade Federal de Minas Gerais (UFMG), Belo Horizonte, 2014. 